\title{
Seasonality, risk factors and burden of
}

\section{community-acquired pneumonia in COPD patients: a population database study using linked health care records}

\author{
This article was published in the following Dove Press journal: \\ International Journal of COPD \\ 17 January 2017 \\ Number of times this article has been viewed
}

\author{
Nicholas P Williams ${ }^{1,2}$ \\ Ngaire A Coombs ${ }^{3}$ \\ Matthew J Johnson ${ }^{4}$ \\ Lynn K Josephs ${ }^{3,4}$ \\ Lucy A Rigge ${ }^{2,4}$ \\ Karl J Staples ${ }^{2}$ \\ Mike Thomas 1,3,4 \\ Tom MA Wilkinson 1,2,4 \\ 'Southampton NIHR Respiratory \\ Biomedical Research Unit, \\ Southampton General Hospital, \\ ${ }^{2} \mathrm{Clinical}$ and Experimental Sciences, \\ Faculty of Medicine, University \\ of Southampton, Southampton \\ General Hospital, ${ }^{3}$ Primary Care \\ and Population Sciences, Faculty \\ of Medicine, Southampton General \\ Hospital, ${ }^{4}$ NIHR CLAHRC Wessex, \\ Faculty of Health Sciences, University \\ of Southampton, Southampton \\ General Hospital, Southampton, UK
}

\begin{abstract}
Background: Community-acquired pneumonia (CAP) is more common in patients with COPD than in the adult general population, with studies of hospitalized CAP patients consistently reporting COPD as a frequent comorbidity. However, despite an increasing recognition of its importance, large studies evaluating the incidence patterns over time, risk factors and burden of CAP in COPD are currently lacking.
\end{abstract}

Methods: A retrospective observational study using a large UK-based database of linked primary and secondary care records was conducted. Patients with a diagnosis of COPD aged $\geq 40$ years were followed up for 5 years from January 1,2010. CAP and exacerbation episodes were identified from hospital discharge data and primary care coding records, and rates were calculated per month, adjusting for mortality, and displayed over time. In addition, baseline factors predicting future risk of CAP and hospital admission with CAP were identified.

Results: A total of 14,513 COPD patients were identified: $13.4 \%(n=1,938)$ had $\geq 1$ CAP episode, of whom $18.8 \%$ suffered from recurrent $(\geq 2)$ CAP. Highest rates of both CAP and exacerbations were seen in winter. A greater proportion of frequent, compared to infrequent, exacerbators experienced recurrent CAP (5.1\% versus $2.0 \%$, respectively, $P<0.001$ ); $75.6 \%$ of CAP episodes were associated with hospital admission compared to $22.1 \%$ of exacerbations. Older age and increasing grade of airflow limitation were independently associated with increased odds of CAP and hospital admission with CAP. Other independent predictors of future CAP included lower body mass index, inhaled corticosteroid use, prior frequent exacerbations and comorbidities, including ischemic heart disease and diabetes.

Conclusion: CAP in COPD demonstrates clear seasonal patterns, with patient characteristics predictive of the odds of future CAP and hospital admission with CAP. Highlighting this burden of COPD-associated CAP during the winter period informs us of the likely triggers and the need for more effective preventive strategies.

Keywords: COPD exacerbations, exacerbation frequency, community-acquired pneumonia, comorbidity

\section{Introduction}

Clinical and Experimental Sciences, Faculty of Medicine, Sir Henry Wellcome Laboratories, University of Southampton, Southampton General Hospital, Mailpoint 810, Tremona Road, Southampton SOI 6 6YD, UK

Tel +44238I204479

Email npwilliams@doctors.org.uk
Community-acquired pneumonia (CAP) is a major cause of morbidity, mortality and health care burden globally. ${ }^{1,2}$ Certain population groups are more susceptible, particularly the elderly and those with chronic conditions such as COPD., ${ }^{3,4}$ The prevalence of COPD increases with age and is estimated to affect $\sim 210$ million people globally, and therefore this population contributes significantly to the overall disease burden of CAP. ${ }^{5,6}$ 
The clinical course of COPD is interspersed by episodes of symptomatic deterioration, termed exacerbations. CAP and exacerbations can be difficult to distinguish clinically, and there remains no clear consensus on whether they represent distinct events or are in fact a continuum. Exacerbations are highly seasonal, with increasing rates seen in the winter months, adding further to the pressures already experienced by overstretched health care providers at this time of year. ${ }^{7,8}$ The winter peak coincides with the increased activity of viral infection, and a causal relationship has been proposed. ${ }^{9}$ Although exacerbations are more frequent in winter, it is not known whether COPD-associated CAP has a similar seasonal pattern. In Europe, hospitalizations due to CAP are increasing, with COPD a frequently encountered comorbidity. ${ }^{10,11}$ Reports suggest that patients with COPD hospitalized with CAP present with more severe symptoms and have longer hospital stays and increased need for ICU admission. ${ }^{12-14} \mathrm{CAP}$ is common in the natural history of COPD, with a much higher incidence compared to that of the adult general population. ${ }^{4}$ Furthermore, in a UK-based audit, $18 \%$ of COPD patients requiring hospitalization for acute respiratory illness had consolidation evident on chest $\mathrm{X}$-ray, diagnostic of CAP.${ }^{15}$ Recent reports have highlighted an increased risk of CAP associated with inhaled corticosteroid (ICS) use in COPD patients, underlining the need for stratification of patients for ICS use to include an estimation of this risk. ${ }^{16,17}$ Therefore, COPD-associated CAP is particularly relevant considering the aging global population and will have important implications for future antibiotic usage and health care resources.

Despite the greater incidence of CAP in COPD compared to the adult general population, it remains a relatively infrequent event compared to exacerbations. Consequently, the true burden of CAP in COPD has been largely overlooked and limited to predominantly cross-sectional analyses of hospitalized patients. ${ }^{18,19}$ Analysis of large population databases can provide a "real-world" perspective of incidence patterns, health care usage and risk factors of CAP in COPD and, thus, an understanding of the likely triggers, susceptibilities and socioeconomic burden of what still remains a poorly understood event in the natural history of many COPD patients. This is key to guiding future, targeted research, focusing on preventative strategies in vulnerable patient groups.

Linked primary and secondary health care records have the potential to improve the accuracy of disease incidence estimates compared to stand-alone records..$^{20}$ Therefore, using the Hampshire Health Record Analytical (HHRA) database, an anonymized database of linked health care records covering $\sim 75 \%$ of primary care practices in Hampshire, Southern England, we sought to describe the seasonal patterns, hospital admissions and risk factors for CAP, among patients with COPD.

\section{Methods}

\section{Study design and population}

A retrospective, observational cohort design was used. Patients were defined as having COPD and eligible for inclusion if they had $\geq 1$ COPD-specific Read code (standard UK classification of clinical terms for electronic coding ${ }^{21}$ in their primary care record at any time prior to January 1, 2010, and were aged $\geq 40$ years at the start of the study. Follow-up ran for 5 years from January 1, 2010, until December 31, 2014.

The HHRA database was used for data collection (Supplementary material). Briefly, it represents a large electronic database of individual patient-anonymized primary and secondary care records, providing a single source of linked routine health data for patients living in Hampshire, Southern England. At the time of the study, the HHRA contained records covering $\sim 1.4$ million patients from $>140$ primary care practices.

Use of the HHRA database for research is regulated by the Hampshire Health Record Information Governance Group (HHRIGG) and National Health Service (NHS) South, Central and West Commissioning Support Unit. NHS data systems entitle patients to opt-out of consenting to storage and use of personal information for analytical purposes. Furthermore, as the HHRA data are anonymized, it is not possible to identify patients; as such, and as confirmed by local research governance (University of Southampton Research, Integrity and Governance Team), formal ethical approval and written informed consent from all participants were not required for this study.

\section{Demographics and clinical factors}

Data were collected on sex, age, weight, height, body mass index (BMI) and disease severity by Global Initiative for Obstructive Lung Disease (GOLD) stage at the most recently recorded time point prior to the study start date, within a preassigned limit of 2 years. Comorbidities were identified using Read code lists and included as present if recorded at any time prior to the study start. Usage of concurrent therapies for COPD was included if $\geq 1$ prescription was evident in the 6 months prior to the study start, with the exception of oral corticosteroids (OCSs), where frequent use was defined as $\geq 4$ prescriptions in the year prior to the study start. Code lists for all the covariates included are available on request. 


\section{COPD-associated CAP}

CAP episodes were identified either from a relevant International Classification of Diseases Version 10 (ICD-10) code in the primary diagnostic position following an inpatient hospital stay or emergency department (ED) attendance or from a physician Read-coded diagnosis of CAP. In order to avoid capturing multiple-coded events for one illness as different episodes, single-coded CAP events were grouped into clusters. Clusters were defined as the number of CAP events occurring within a continuous 70-day period, with the date of the first event regarded as the index date. ${ }^{4} \mathrm{~A}$ period of at least 2 event-free weeks following CAP episodes was required in order to avoid labeling prolonged recording of events for the same illness, as new episodes.

\section{COPD exacerbations}

Exacerbations were defined as either, 1) a physician Readcoded diagnosis of exacerbation, 2) the prescription of specific antibiotics or OCS on the same day or up to 7 days before or after a COPD diagnostic or symptom Read code, or 3) a relevant respiratory ICD-10 code in the primary or secondary diagnostic positions, following an inpatient hospital stay or ED attendance. A continuous 21-day period defined an episode, with 2 event-free weeks required to separate exacerbations.

\section{Seasonality}

The month of the index event (CAP or exacerbation) date was taken as the month of episode occurrence. Winter was defined as December to February and summer as June to August.

\section{Statistical analysis}

Analyses were performed using SPSS version 22. CAP and exacerbation rates were calculated per month, adjusting for mortality, and displayed over time. Categorical variables are presented as number (percentage). Chi-square tests were used to compare data between groups with and without a diagnosis of CAP. Multivariate logistic regression was then used to identify adjusted odds ratios (ORs) and $95 \%$ confidence intervals (95\% CIs) for having $\geq 1$ CAP episode versus none, in patients with complete data, who either survived until the end of the observation period or died following CAP. Covariates reaching significance from the bivariate analysis were included in the multivariate model. To identify risk factors for hospital admission during CAP, we used STATA to conduct conditional logistic regression, treating subject as a random effect. This accounted for the over-representation of some patients (ie, those experiencing $>1 \mathrm{CAP}$ ). A $P$-value of $<0.05$ was considered statistically significant.
Results

\section{Population characteristics}

The study cohort consisted of 14,513 patients with a diagnosis of COPD. The mean \pm standard deviation (SD) age at the start of the study period was $70.3 \pm 10.8$ years; $53.6 \%$ were male and $33.5 \%$ were current smokers (Table 1). Of the cohort in which lung function data were available $(n=10,358)$, mean \pm SD forced expiratory volume in 1 second $\left(\mathrm{FEV}_{1}\right)$

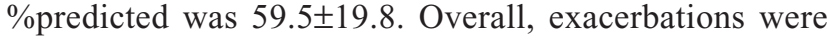
more prevalent than CAP. The incidence rate for CAP was 37.6 per 1,000 person-years, with $13.4 \%(n=1,938)$ experiencing at least one CAP, and of these, $18.8 \%(n=364)$ had more than one.

\section{Seasonality of CAP, exacerbations and hospital admissions}

Figure 1A and $\mathrm{B}$ displays the total monthly rates of CAP and exacerbations across 5 years, while Figure $1 \mathrm{C}$ and $\mathrm{D}$ displays the rates averaged into 1 calendar year. A clear seasonal pattern is evident with highest rates of CAP in the winter, especially December, compared to other periods of the year. Median monthly CAP rates were 4.0 per 1,000 person-months in winter versus 2.8 in summer $(P=0.003)$. Similarly, for exacerbations, higher rates occurred in winter, with lower rates in summer ( 83.6 versus 60.5 per 1,000 person-months, respectively, $P<0.001)$.

A total of 2,413 CAP episodes were identified over 5 years. Trends in hospital admissions associated with CAP closely followed the seasonal distribution of total CAP episodes, with $75.6 \%$ of CAP associated with hospital admission, compared to only $22.1 \%$ of exacerbations.

\section{Risk factors for CAP}

Using multivariate logistic regression modeling and controlling for potential confounders, factors independently predicting CAP risk were identified (Table 2). The odds of experiencing CAP increased with age, with patients aged 60-79 and $\geq 80$ years having higher odds than those aged 40-59 years (OR 1.67, 95\% CI 1.30-2.16 and OR 4.10, 95\% CI 3.05-5.49, respectively). BMI was also strongly associated with the odds of CAP, with those underweight having higher odds (OR 1.82, 95\% CI 1.27-2.62) than those of normal weight. Conversely, the odds of CAP in overweight and obese patients was $\sim 30 \%$ lower (OR 0.73 , $95 \%$ CI $0.61-0.87$ and OR $0.70,95 \%$ CI 0.58-0.85, respectively) than that in patients of normal weight. Increasing grade of airflow limitation was associated with higher odds of CAP, with GOLD stage IV associated with almost three 
Table I Patient demographics and baseline clinical characteristics of the total COPD cohort, by presence or absence of a CAP diagnosis over the 5-year study period

\begin{tabular}{|c|c|c|c|c|}
\hline Characteristic & Total & No CAP & $\geq$ I CAP & $P$-value \\
\hline Number of patients & $14,5 \mid 3$ & $12,575(86.6)$ & $1,938(13.4)$ & \\
\hline Sex (male) & $7,775(53.6)$ & $6,707(53.3)$ & $\mathrm{I}, 068(55 . \mathrm{I})$ & 0.145 \\
\hline Age (years) & & & & $<0.001$ \\
\hline $40-59$ & $2,347(16.2)$ & $2,17 \mid(\mid 7.3)$ & $176(9.1)$ & \\
\hline $60-79$ & $9,044(62.3)$ & $7,839(63.1)$ & $\mathrm{I}, 105(57.0)$ & \\
\hline$\geq 80$ & $3,122(21.5)$ & $2,465(19.6)$ & $657(33.9)$ & \\
\hline Smoking status $(n=12,972)$ & & & & 0.027 \\
\hline Current & $4,859(33.5)$ & $4,255(37.8)$ & $604(35.1)$ & \\
\hline Ex/never & $8,113(55.9)$ & $6,994(62.2)$ & $1,119(64.9)$ & \\
\hline BMI, $\mathrm{kg} / \mathrm{m}^{2}(\mathrm{n}=9,235)$ & & & & $<0.001$ \\
\hline Underweight $(<18.5)$ & $340(3.7)$ & $275(3.4)$ & $65(5.5)$ & \\
\hline Normal weight (18.5-24.9) & $2,911(31.5)$ & $2,483(30.9)$ & $428(36.1)$ & \\
\hline Overweight (25.0-29.9) & $3,247(35.2)$ & $2,874(35.7)$ & $373(31.4)$ & \\
\hline Obese $(\geq 30)$ & $2,737(29.6)$ & $2,416(30.0)$ & $321(27.0)$ & \\
\hline Prior CAP & $358(2.5)$ & $253(2.0)$ & $105(5.4)$ & $<0.001$ \\
\hline Exacerbation frequency & & & & $<0.00$ I \\
\hline Frequent ( $\geq 2$ per year) & $2,496(I 7.2)$ & $2,004(I 5.9)$ & $492(25.4)$ & \\
\hline Infrequent ( $<2$ per year) & I2,0|7 (82.8) & $|0,57|(84 . \mid)$ & $\mathrm{I}, 446(74.6)$ & \\
\hline \multicolumn{5}{|l|}{ Pharmacotherapy } \\
\hline ICS use & $7,806(53.8)$ & $6,348(50.5)$ & I, I I 2 (57.9) & $<0.001$ \\
\hline Frequent OCS use & I,202 (8.3) & $925(7.4)$ & $277(14.3)$ & $<0.001$ \\
\hline LABA use & $6,376(43.9)$ & $5,353(42.6)$ & $\mathrm{I}, 023(52.8)$ & $<0.001$ \\
\hline LAMA use & $4,046(27.9)$ & $3,323(26.4)$ & $723(37.3)$ & $<0.001$ \\
\hline Prior pneumococcal vaccine & $4,790(33)$ & $4,167(33.1)$ & $623(32.1)$ & 0.388 \\
\hline \multicolumn{5}{|l|}{ Comorbidity } \\
\hline IHD & $2,853(19.7)$ & $2,347(\mid 8.7)$ & $506(26.1)$ & $<0.001$ \\
\hline Heart failure & $931(6.4)$ & $739(5.9)$ & $192(9.9)$ & $<0.00$ I \\
\hline Hypertension & $6,043(41.6)$ & $5,146(40.9)$ & $897(46.3)$ & $<0.00$ I \\
\hline Diabetes mellitus & I,978 (I3.6) & I,622 (I2.9) & $356(18.4)$ & $<0.001$ \\
\hline Peripheral vascular disease & $852(5.9)$ & $692(5.5)$ & $160(8.3)$ & $<0.001$ \\
\hline Hyperlipidemia & $2,514(17.5)$ & $2,203(I 7.5)$ & $338(17.4)$ & 0.933 \\
\hline Cerebrovascular disease & $\mathrm{I}, 397(9.6)$ & I,I I 5 (8.9) & $282(14.6)$ & $<0.001$ \\
\hline Dementia & $306(2.1)$ & $245(1.9)$ & $61(3.1)$ & 0.001 \\
\hline Asthma & $6,989(48.2)$ & $5,982(47.6)$ & $\mathrm{I}, 007(52.0)$ & $<0.001$ \\
\hline GORD & $\mathrm{I}, 423(9.8)$ & I, I $98(9.5)$ & $225(11.6)$ & 0.004 \\
\hline Anxiety or depression & $5,380(37.1)$ & $4,643(36.9)$ & $737(38.0)$ & 0.348 \\
\hline Osteoporosis & $955(6.6)$ & $780(6.2)$ & $175(9.0)$ & $<0.001$ \\
\hline CKD & $2,263(I 5.6)$ & $\mathrm{I}, 836(\mid 4.6)$ & $427(22.0)$ & $<0.001$ \\
\hline Connective tissue disease & $350(2.4)$ & $280(2.2)$ & $70(3.6)$ & $<0.001$ \\
\hline GOLD staging $(n=\mid 0,358)$ & & & & $<0.001$ \\
\hline I & $\mathrm{I}, 524(\mathrm{I} 4.7)$ & I,387 (I5.4) & $137(10.0)$ & \\
\hline II & $5,396(52.1)$ & $4,795(53.3)$ & $601(43.9)$ & \\
\hline III & $2,803(27.1)$ & $2,299(25.6)$ & $504(36.8)$ & \\
\hline IV & $635(6.1)$ & $509(5.7)$ & $126(9.2)$ & \\
\hline
\end{tabular}

Notes: Data are presented as frequencies (\%). P-values from chi-square test.

Abbreviations: BMI, body mass index; CAP, community-acquired pneumonia; CKD, chronic kidney disease; GOLD, Global Initiative for Obstructive Lung Disease; GORD, gastroesophageal reflux disease; ICS, inhaled corticosteroid; IHD, ischemic heart disease; LABA, long-acting beta-agonist; LAMA, long-acting muscarinic antagonist; OCS, oral corticosteroid.

times the odds compared to GOLD stage I (OR 2.86, 95\% CI 2.00-4.09).

Additional factors independently associated with increased odds of CAP were a prior history of CAP and comorbid diseases, including ischemic heart disease (IHD), diabetes and chronic kidney disease (CKD).

\section{Exacerbation frequency and CAP risk}

A history of frequent exacerbations, defined as $\geq 2$ exacerbations in the year prior to the study start date, appears to be predictive of future CAP. Frequent exacerbators had almost $30 \%$ higher odds of having CAP over the study period (OR 1.29, 95\% CI 1.08-1.54), compared to infrequent 

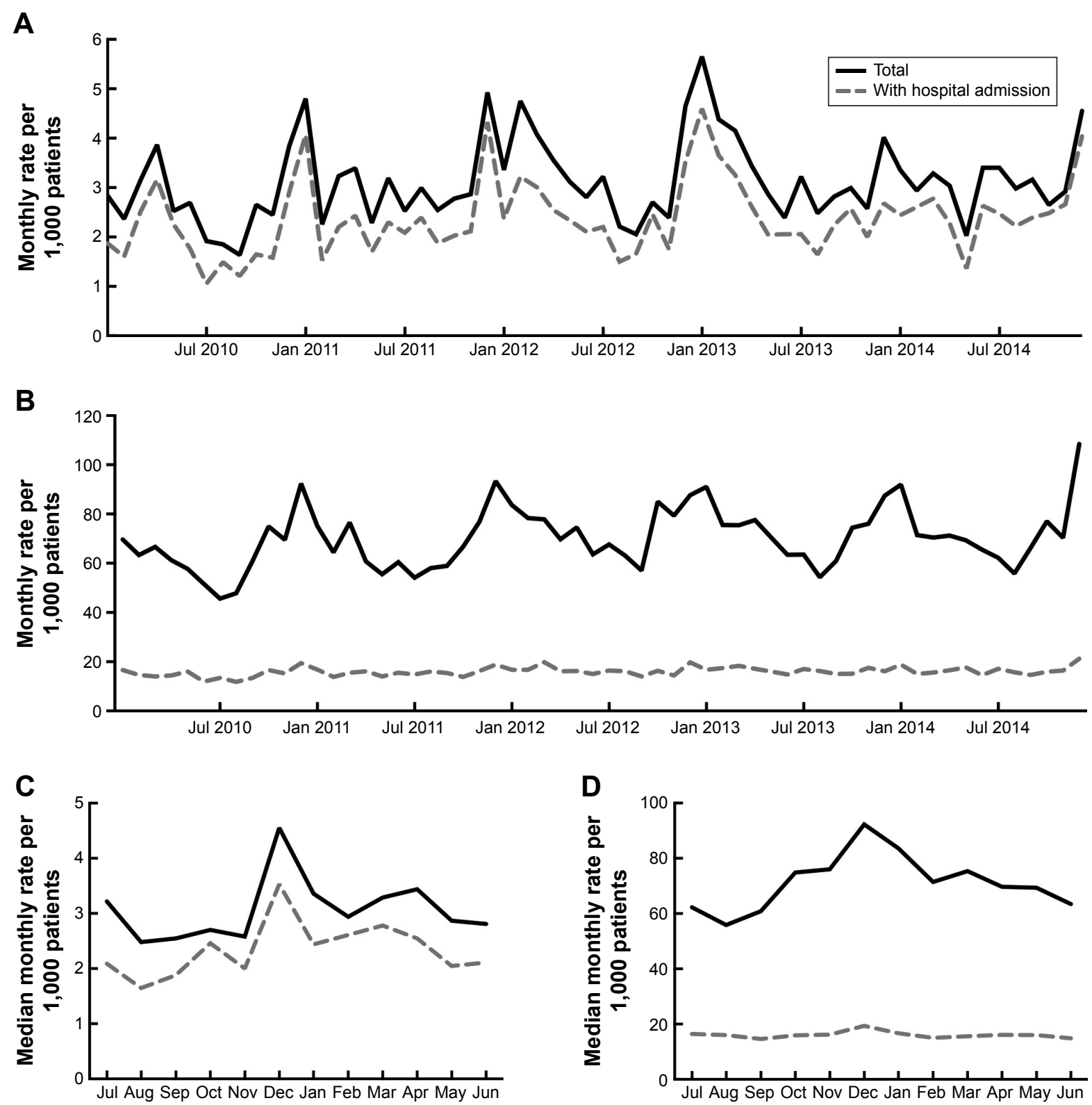

Figure I Seasonality of CAP and exacerbations.

Notes: Total monthly rates and rate of hospital admission for CAP (A) and exacerbations (B) in COPD over 5 years. (C and D) Represent the data for CAP and exacerbations, respectively, averaged over I calendar year and displayed as the median monthly rate.

Abbreviation: CAP, community-acquired pneumonia.

exacerbators. In addition, a greater proportion of frequent exacerbators experienced recurrent CAP over 5 years, compared with infrequent exacerbators $(5.1 \%$ versus $2.0 \%$, $P<0.001$ ) (Figure 2).

\section{Risk factors for hospital admission associated with CAP}

Conditional logistic regression, accounting for subject effect, was used to examine associations between patient characteristics and the odds of hospital admission during CAP episodes (n patients $=1,368, \mathrm{n} \mathrm{CAP}=1,721$ ). Increasing age and grade of airflow limitation were independently associated with increased odds of hospital admission during CAP (Table 3).

\section{All-cause mortality}

A total of 2,877 deaths occurred over the 5-year study period. All-cause mortality followed a similar seasonal distribution to CAP and exacerbations (Figure 3); 880 (30.6\%) deaths occurred in winter compared to $602(20.9 \%)$ in summer. 
Table 2 Adjusted ORs and 95\% Cls for predictors of 5-year CAP risk

\begin{tabular}{|c|c|c|c|}
\hline$n=6,805$ & OR & $95 \% \mathrm{Cl}$ & $P$-value \\
\hline \multicolumn{4}{|l|}{ Sex } \\
\hline Female & Reference & & \\
\hline Male & 1.182 & $1.015-1.376$ & 0.031 \\
\hline \multicolumn{4}{|l|}{ Age (years) } \\
\hline $40-59$ & Reference & & \\
\hline $60-79$ & 1.674 & $1.296-2.161$ & $<0.00 \mathrm{I}$ \\
\hline$\geq 80$ & 4.096 & $3.053-5.494$ & $<0.00 \mathrm{I}$ \\
\hline \multicolumn{4}{|l|}{ Smoking status } \\
\hline Ex/never & Reference & & \\
\hline Current & 1.316 & $1.12 \mathrm{I}-1.544$ & 0.001 \\
\hline \multicolumn{4}{|l|}{$\mathrm{BMI}, \mathrm{kg} / \mathrm{m}^{2}$} \\
\hline Underweight $(<18.5)$ & 1.823 & $1.267-2.624$ & 0.001 \\
\hline Normal weight (I8.5-24.9) & Reference & & \\
\hline Overweight (25-29.9) & 0.729 & $0.610-0.872$ & 0.001 \\
\hline Obese $(\geq 30)$ & $0.70 \mathrm{I}$ & $0.576-0.853$ & $<0.001$ \\
\hline Prior CAP & 2.228 & $1.453-3.415$ & $<0.00 \mathrm{I}$ \\
\hline \multicolumn{4}{|l|}{ Exacerbation frequency } \\
\hline Infrequent ( $<2$ per year) & Reference & & \\
\hline Frequent ( $\geq 2$ per year) & 1.291 & $1.080-1.543$ & 0.005 \\
\hline \multicolumn{4}{|l|}{ Pharmacotherapy } \\
\hline ICS use & 1.229 & $1.001-1.508$ & 0.049 \\
\hline Frequent OCS use & 1.934 & $1.539-2.431$ & $<0.00 \mathrm{I}$ \\
\hline LABA use & 1.136 & $0.936-1.379$ & 0.196 \\
\hline LAMA use & 1.398 & $1.199-1.628$ & $<0.00 \mathrm{I}$ \\
\hline \multicolumn{4}{|l|}{ Comorbidities } \\
\hline IHD & 1.312 & I.102-1.562 & 0.002 \\
\hline Heart failure & 1.415 & $1.065-1.88 \mid$ & 0.017 \\
\hline Hypertension & 1.081 & $0.929-1.258$ & 0.315 \\
\hline Diabetes mellitus & 1.736 & $1.438-2.097$ & $<0.00 \mathrm{I}$ \\
\hline Peripheral vascular disease & 1.364 & $1.044-1.784$ & 0.023 \\
\hline Cerebrovascular disease & 1.325 & $1.050-1.672$ & 0.018 \\
\hline Dementia & 2.219 & I.27I-3.877 & 0.005 \\
\hline Asthma & 1.049 & $0.90 \mathrm{I}-1.220$ & 0.538 \\
\hline GORD & 1.179 & $0.948-1.467$ & 0.138 \\
\hline CKD & 1.322 & $1.093-1.600$ & 0.004 \\
\hline Osteoporosis & 1.173 & $0.882-1.559$ & 0.273 \\
\hline Connective tissue disease & 1.688 & I.I10-2.565 & 0.014 \\
\hline \multicolumn{4}{|l|}{ GOLD stage } \\
\hline I & Reference & & \\
\hline ॥ & 1.296 & $1.018-1.649$ & 0.035 \\
\hline III & 2.239 & I.735-2.89| & $<0.00 \mathrm{I}$ \\
\hline IV & 2.861 & $2.003-4.085$ & $<0.001$ \\
\hline
\end{tabular}

Notes: Multivariate logistic regression model of 6,805 patients with complete data, who either survived until the end of the 5-year observation period or died during the observation period following a CAP episode and were not lost to follow-up. For comorbidities and pharmacotherapy, not having the comorbidity and not using the drug were taken as the reference.

Abbreviations: $\mathrm{BMI}$, body mass index; $\mathrm{CAP}$, community-acquired pneumonia; $\mathrm{Cl}$, confidence interval; CKD, chronic kidney disease; GORD, gastroesophageal reflux disease; ICS, inhaled corticosteroid; IHD, ischemic heart disease; LABA, long-acting beta-agonist; LAMA, long-acting muscarinic antagonist; GOLD, Global Initiative for Obstructive Lung Disease; OCS, oral corticosteroid; OR, odds ratio.

\section{Discussion}

This is the first population-based study showing the seasonal trends of CAP and exacerbations among people with COPD, using linked primary and secondary care data sources. The incidence rate of 37.6 CAP cases per 1,000 person-years

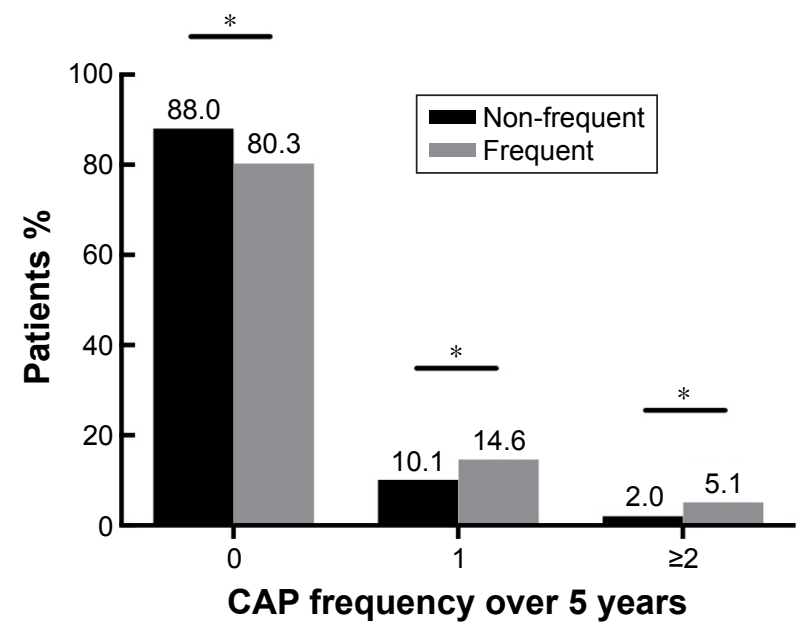

Figure 2 Associations between CAP frequency and the frequent exacerbator phenotype over 5 years.

Notes: $P$-values from chi-square test. $* P<0.001$.

Abbreviation: CAP, community-acquired pneumonia.

compares to that of 22.4 reported by Mullerova et $\mathrm{al}^{4}$ in COPD patients and 7.99 reported by Millett et $\mathrm{al}^{3}$ of adults aged $\geq 65$ years, not limited to COPD.

A total of $13.4 \%$ of our study population had CAP over 5 years, with almost a fifth of these having more than one episode. CAP occurrence is to some extent a predictable phenomenon and tracks with exacerbation frequency. Moreover, there are potentially modifiable factors such as BMI and concurrent medication use, which could form the basis

Table 3 Adjusted OR and $95 \% \mathrm{Cl}$ for hospital admission with CAP

\begin{tabular}{|c|c|c|c|}
\hline$n=1,72 I$ & OR & $95 \% \mathrm{Cl}$ & $P$-value \\
\hline \multicolumn{4}{|l|}{ Sex } \\
\hline Female & Reference & & \\
\hline Male & 1.104 & $0.779-1.565$ & 0.576 \\
\hline \multicolumn{4}{|l|}{ Age (years) } \\
\hline $40-59$ & Reference & & \\
\hline $60-79$ & $\mathrm{I} .875$ & $1.050-3.348$ & 0.034 \\
\hline$\geq 80$ & 4.559 & $2.34 \mid-8.878$ & $<0.001$ \\
\hline ICS use & 1.428 & $0.973-2.097$ & 0.069 \\
\hline Prior CAP & 0.549 & $0.255-1.182$ & 0.126 \\
\hline \multicolumn{4}{|l|}{ Exacerbation frequency } \\
\hline Infrequent ( $<2$ per year) & Reference & & \\
\hline Frequent ( $\geq 2$ per year) & 1.143 & $0.780-1.676$ & 0.494 \\
\hline \multicolumn{4}{|l|}{ GOLD } \\
\hline I & Reference & & \\
\hline ॥ & 2.325 & $1.307-4.134$ & 0.004 \\
\hline III & 2.784 & $1.530-5.068$ & 0.001 \\
\hline IV & 4.536 & $1.960-10.50 \mid$ & $<0.001$ \\
\hline
\end{tabular}

Note: Multivariate conditional logistic regression model, including the patient as a random effect, of I,72। CAP episodes (occurring in 1,368 patients) with complete data.

Abbreviations: CAP, community-acquired pneumonia; $\mathrm{Cl}$, confidence interval; ICS, inhaled corticosteroid; GOLD, Global Initiative for Obstructive Lung Disease; OR, odds ratio. 


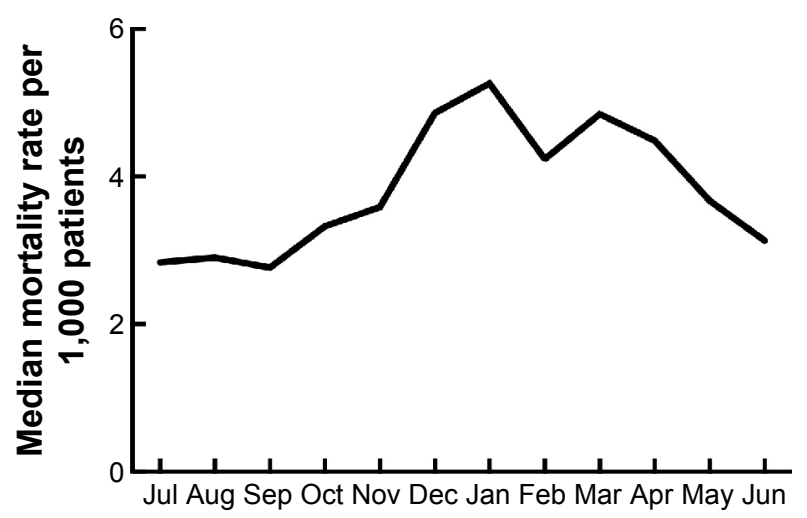

Figure 3 All-cause mortality rate over 5 years, averaged into I calendar year and displayed as the median monthly rate.

of targeted risk-reducing strategies. Greater understanding of the underlying mechanisms is therefore required to establish why some patients are more susceptible to CAP than others.

CAP occurred more commonly in the winter, compared to other times of the year. Similarly for exacerbations, and in line with findings from the Towards a Revolution in COPD Health (TORCH) study, a clear and consistent seasonal pattern from year to year was seen. ${ }^{7}$ Importantly, our study population differs from the TORCH study, as it benefits from providing a true insight into real-world population trends across all severity of COPD, as compared to a highly selected patient cohort with more severe disease.

The majority of reports to date suggest that CAP in COPD is caused primarily by bacterial infection. ${ }^{18,22,23}$ However, the microbiological profile of CAP in adult patients without COPD has a proven seasonal basis with an important role attributed to viral infection. ${ }^{24,25}$ Holter et $\mathrm{al}^{24}$ demonstrated that CAP occurring in the winter and spring is associated with a greater frequency of bacterial-viral co-infection, supporting the results from an earlier study by Lieberman et al, ${ }^{25}$ showing greater frequencies of respiratory viral infection ascribed to CAP in these seasons. There is also a large body of evidence supporting the role of influenza infection and secondary bacterial pneumonia; ${ }^{26}$ yet, this finding is not apparent in reports for CAP in COPD. A separate analysis of our data (not shown) for each individual influenza season during the 5-year period indicated no strong associations between reduced CAP rates and receipt of influenza vaccination. Certainly, our data show a greater rate of CAP in the winter compared to other times of the year, suggesting that respiratory viral infection may have an important causative role. Indeed, environmental factors, notably lower temperatures and changes in relative humidity during winter, may favor the survival of respiratory viruses and increase host susceptibility to infection. ${ }^{9}$ It was not until relatively recently that viral infection and cold symptoms, a marker of putative viral infection, were established as important determinants of COPD exacerbations, leading to worsening symptoms and prolonged recovery. ${ }^{27,28}$ With the proven seasonality of exacerbations and now CAP in COPD, viral infection must be considered as a key early determinant in the sequence of events leading to both exacerbations and CAP in COPD patients.

Like other reports, we found that increasing age, poorer lung function, lower BMI and comorbid disease, particularly IHD, diabetes and CKD, were all independently associated with future CAP risk. ${ }^{4,16}$ It is already known that the elderly, especially those aged $>65$ years, are particularly susceptible to developing CAP. ${ }^{29}$ The mechanisms are complex, but age-influenced immune system dysregulation, predisposing to infection risk is likely to be of importance. On a population-based level, physicians may be more likely to diagnose respiratory infection in older, frailer patients, and yet, we found no observed influence of age on the risk of exacerbation (data not shown). Like previous studies, we show the association between lower BMI and increased CAP risk and higher BMI with reduced risk, compared to normal weight patients. ${ }^{4,16}$ This perceived protective effect of a higher BMI has also been reported previously in studies not limited to COPD patients. ${ }^{30}$ Yet, despite the underlying reasons remaining unclear, it could still provide a potentially useful target for risk-reducing interventions.

A susceptibility to frequent exacerbations is now a wellestablished COPD phenotype and has been shown to be fairly consistent over time. ${ }^{31}$ Frequent exacerbators are more susceptible to viral infection and have higher levels of airway inflammation at stable state, both proposed as possible underlying mechanisms. ${ }^{32}$ We have established prior exacerbation frequency as an independent risk factor for CAP, with an increased proportion of frequent exacerbators experiencing recurrent CAP. However, a prior history of frequent exacerbations does not appear to influence the likelihood of more severe (ie, hospitalized) CAP events. Furthermore, and in line with a previous report, we show that a prior history of CAP is a risk factor for future CAP. ${ }^{4}$ Whether the mechanisms underlying exacerbation frequency and CAP susceptibility are the same requires further research.

As anticipated, our study re-confirms ICS use as an independent risk factor for future CAP, with a further trend evident between ICS use and increased odds of hospital admission associated with CAP. Interestingly, long-acting muscarinic 
antagonist (LAMA) use was independently associated with increased odds of CAP. Published data have shown that in COPD patients with severe disease $\left(\mathrm{FEV}_{1}<50 \%\right.$ predicted), LAMA use appears to confer less risk of CAP than ICS use. ${ }^{17}$ However, data pertaining to CAP risk with LAMA use in large population analyses of COPD patients and importantly across all disease severities are currently lacking.

The burden of respiratory-related health care utilization and hospital attendances, especially for COPD and CAP, is substantial, with the winter period being particularly pressured. ${ }^{33,34}$ In line with an increased rate of CAP in winter, we have shown that the number of hospital admissions with CAP also increases substantially, proportionally much more so than with exacerbations. Patients who required hospital admission were older and had greater severity of underlying COPD, representing a vulnerable group and those most likely to impose a greater resource burden. ${ }^{35}$ More than $75 \%$ of CAP episodes were associated with hospital admission, which is much higher than most reports for the adult general population ${ }^{36,37}$ and probably indicates a lower threshold for admitting COPD patients to hospital, or a manifestation of more severe symptoms. Regardless, with the aging global population and increasing prevalence of COPD, CAP will become a growing future problem in this chronic disease group.

We acknowledge that this study has limitations. We were unable to validate CAP diagnoses with independent assessment of chest X-ray findings, as this was a large population database containing anonymized data in which radiological features were assessed by the attending physician. However, Skull et $\mathrm{al}^{38}$ have reported that ICD-10 codes can be a valid method of retrospectively identifying CAP from medical records. A large proportion of CAP in our study was associated with hospital admission and based on hospital discharge diagnoses, and therefore it is highly likely that a chest X-ray was performed in these cases, confirming the diagnosis.

With regard to our study population, we included patients with a Read-coded diagnosis of COPD and did not require spirometric confirmation for study inclusion. However, this method has been shown to accurately identify COPD patients from UK primary care records with spirometry only marginally improving the accuracy. ${ }^{39}$

\section{Conclusion}

Like exacerbations, COPD-associated CAP is highly seasonal, with an increased burden observed over winter. Despite occurring less frequently in the natural history of COPD than exacerbations, its relative impact on health care utilization is considerable, with the most vulnerable patients often at greatest risk of both events. In addition, establishing common risk factors may allow for a prospective estimation of a patient's risk of future CAP, aiding clinicians in treatment and management decisions. Studies, focusing on preventative strategies such as interventions to reduce risk and improve outcomes, including nutritional interventions, treatment stratification and new and improved vaccination programs, are key to tackling the increasing future burden of CAP in at-risk patients, such as those with COPD.

\section{Acknowledgments}

The authors thank NHS South, Central and West Commissioning Support Unit and the Hampshire Health Record Information Governance Group for their support and for provision of access to HHRA data. This article presents independent research supported by the National Institute for Health Research Collaboration for Leadership in Applied Health Research and Care (NIHR CLAHRC) Wessex. The views expressed in this publication are those of the authors and not necessarily those of the NHS, the NIHR, or the Department of Health.

\section{Disclosure}

The authors report no conflicts of interest in this work.

\section{References}

1. Welte T, Torres A, Nathwani D. Clinical and economic burden of community-acquired pneumonia among adults in Europe. Thorax. 2012;67(1):71-79.

2. Quan TP, Fawcett NJ, Wrightson JM, et al; Infections in Oxfordshire Research Database (IORD). Increasing burden of community-acquired pneumonia leading to hospitalisation, 1998-2014. Thorax. 2016;71(6): 535-542.

3. Millett ER, Quint JK, Smeeth L, Daniel RM, Thomas SL. Incidence of community-acquired lower respiratory tract infections and pneumonia among older adults in the United Kingdom: a population-based study. PLoS One. 2013;8(9):e75131.

4. Mullerova H, Chigbo C, Hagan GW, et al. The natural history of community-acquired pneumonia in COPD patients: a population database analysis. Respir Med. 2012;106(8):1124-1133.

5. Raherison C, Girodet PO. Epidemiology of COPD. Eur Respir Rev. 2009;18(114):213-221.

6. Bousquet J, Kiley J, Bateman ED, et al. Prioritised research agenda for prevention and control of chronic respiratory diseases. Eur Respir J. 2010;36(5):995-1001.

7. Jenkins CR, Celli B, Anderson JA, et al. Seasonality and determinants of moderate and severe COPD exacerbations in the TORCH study. Eur Respir J. 2012;39(1):38-45.

8. Rabe KF, Fabbri LM, Vogelmeier C, et al. Seasonal distribution of COPD exacerbations in the prevention of exacerbations with tiotropium in COPD trial. Chest. 2013;143(3):711-719.

9. Donaldson GC, Wedzicha JA. The causes and consequences of seasonal variation in COPD exacerbations. Int J Chron Obstruct Pulmon Dis. 2014;9:1101-1110. 
10. Bardsley M, Blunt I, Davies S, Dixon J. Is secondary preventive care improving? Observational study of 10-year trends in emergency admissions for conditions amenable to ambulatory care. BMJ Open. 2013;3(1):e002007.

11. Trotter CL, Stuart JM, George R, Miller E. Increasing hospital admissions for pneumonia, England. Emerg Infect Dis. 2008;14(5):727-733.

12. Andreassen SL, Liaaen ED, Stenfors N, Henriksen AH. Impact of pneumonia on hospitalizations due to acute exacerbations of COPD. Clin Respir J. 2014;8(1):93-99.

13. Myint PK, Lowe D, Stone RA, Buckingham RJ, Roberts CM. U.K. National COPD Resources and Outcomes Project 2008: patients with chronic obstructive pulmonary disease exacerbations who present with radiological pneumonia have worse outcome compared to those with non-pneumonic chronic obstructive pulmonary disease exacerbations. Respiration. 2011;82(4):320-327.

14. Restrepo MI, Mortensen EM, Pugh JA, Anzueto A. COPD is associated with increased mortality in patients with community-acquired pneumonia. Eur Respir J. 2006;28(2):346-351.

15. Royal College of Physicians. National Chronic Obstructive Pulmonary Disease Audit Programme: Clinical Audit of COPD Exacerbations Admitted to Acute Units in England and Wales 2014. Royal College of Physicians, London; 2015.

16. Crim C, Calverley PM, Anderson JA, et al. Pneumonia risk in COPD patients receiving inhaled corticosteroids alone or in combination: TORCH study results. Eur Respir J. 2009;34(3):641-647.

17. Calverley PM, Stockley RA, Seemungal TA, et al; Investigating New Standards for Prophylaxis in Reduction of Exacerbations (INSPIRE) Investigators. Reported pneumonia in patients with COPD: findings from the INSPIRE study. Chest. 2011;139(3):505-512.

18. Gomez-Junyent J, Garcia-Vidal C, Viasus D, et al. Clinical features, etiology and outcomes of community-acquired pneumonia in patients with chronic obstructive pulmonary disease. PLoS One. 2014;9(8): e105854.

19. Liapikou A, Polverino E, Ewig S, et al. Severity and outcomes of hospitalised community-acquired pneumonia in COPD patients. Eur Respir J. 2012;39(4):855-861.

20. Millett ER, Quint JK, De Stavola BL, Smeeth L, Thomas SL. Improved incidence estimates from linked vs. stand-alone electronic health records. J Clin Epidemiol. 2016;75:66-69.

21. Health and Social Care Information Centre [webpage on the Internet] NHS UK Read Codes Version 2; 2015 . Available from: http://systems. hscic.gov.uk/data/uktc/readcodes. Accessed June 27, 2016.

22. Torres A, Dorca J, Zalacain R, et al. Community-acquired pneumonia in chronic obstructive pulmonary disease: a Spanish multicenter study. Am J Respir Crit Care Med. 1996;154(5):1456-1461.

23. Molinos L, Clemente MG, Miranda B, et al; ASTURPAR Group. Community-acquired pneumonia in patients with and without chronic obstructive pulmonary disease. J Infect. 2009;58(6):417-424.

24. Holter JC, Muller F, Bjorang O, et al. Etiology of community-acquired pneumonia and diagnostic yields of microbiological methods: a 3-year prospective study in Norway. BMC Infect Dis. 2015;15:64.
25. Lieberman D, Lieberman D, Porath A. Seasonal variation in communityacquired pneumonia. Eur Respir J. 1996;9(12):2630-2634.

26. Wunderink RG. Influenza and bacterial pneumonia - constant companions. Crit Care. 2010;14(3):150.

27. Seemungal TA, Donaldson GC, Bhowmik A, Jeffries DJ, Wedzicha JA. Time course and recovery of exacerbations in patients with chronic obstructive pulmonary disease. Am J Respir Crit Care Med.2000;161(5): 1608-1613.

28. Donaldson GC, Law M, Kowlessar B, et al. Impact of prolonged exacerbation recovery in chronic obstructive pulmonary disease. $\mathrm{Am} \mathrm{J}$ Respir Crit Care Med. 2015;192(8):943-950.

29. Prina E, Ranzani OT, Torres A. Community-acquired pneumonia. Lancet. 2015;386(9998):1097-1108.

30. Almirall J, Bolibar I, Serra-Prat M, et al; Community-Acquired Pneumonia in Catalan Countries (PACAP) Study Group. New evidence of risk factors for community-acquired pneumonia: a population-based study. Eur Respir J. 2008;31(6):1274-1284.

31. Hurst JR, Vestbo J, Anzueto A, et al; Evaluation of COPD Longitudinally to Identify Predictive Surrogate Endpoints (ECLIPSE) Investigators. Susceptibility to exacerbation in chronic obstructive pulmonary disease. N Engl J Med. 2010;363(12):1128-1138.

32. Wedzicha JA, Brill SE, Allinson JP, Donaldson GC. Mechanisms and impact of the frequent exacerbator phenotype in chronic obstructive pulmonary disease. BMC Med. 2013;11:181.

33. Almagro P, Hernandez C, Martinez-Cambor P, Tresserras R, Escarrabill J. Seasonality, ambient temperatures and hospitalizations for acute exacerbation of COPD: a population-based study in a metropolitan area. Int J Chron Obstruct Pulmon Dis. 2015;10:899-908.

34. Herrera-Lara S, Fernandez-Fabrellas E, Cervera-Juan A, BlanquerOlivas R. Do seasonal changes and climate influence the etiology of community acquired pneumonia? Arch Bronconeumol. 2013;49(4): $140-145$.

35. McLaughlin JM, Johnson MH, Kagan SA, Baer SL. Clinical and economic burden of community-acquired pneumonia in the Veterans Health Administration, 2011: a retrospective cohort study. Infection. 2015; 43(6):671-680.

36. Lim WS, Baudouin S Sr, George R, et al. British Thoracic Society guidelines for the management of community acquired pneumonia in adults: update 2009. Thorax. 2009;64(suppl 3):iii1-iii55.

37. Sterrantino C, Trifiro G, Lapi F, et al. Burden of community-acquired pneumonia in Italian general practice. Eur Respir J. 2013;42(6):1739-1742.

38. Skull SA, Andrews RM, Byrnes GB, et al. ICD-10 codes are a valid tool for identification of pneumonia in hospitalized patients aged $>$ or $=65$ years. Epidemiol Infect. 2008;136(2):232-240.

39. Quint JK, Mullerova H, DiSantostefano RL, et al. Validation of chronic obstructive pulmonary disease recording in the Clinical Practice Research Datalink (CPRD-GOLD). BMJ Open. 2014;4(7):e005540. 


\section{Supplementary material Methods - data source}

Hampshire Health Record (HHR) and electronic health care data sets

The HHR is an electronic shared care record for people living in Hampshire that provides a single source of linked routine health data for individual patients, collected in "real time", and links data from general practitioner practices and hospitals and recently includes some data from social care. It is able to combine data from many different IT systems. It is not part of the National Summary Care Record but rather is an arrangement local to Hampshire, storing data from a wide range of practices that have "opted in" to the data-sharing scheme. The HHR is used by clinicians to share information and aid clinical decision-making and is currently supported with data supplied by many organizations in the South of England, including local primary care practices and providers of secondary, community and social care.

\section{Hampshire Health Record Analytical (HHRA) database}

The HHRA database is a separate electronic database created for research and analysis to support health improvement and planning. At the time of this study, it included data from $>140$ practices across Hampshire, covering $~ 1.4$ million patients. It shares some of the health data contained within the HHR but in anonymized form to protect patients' identity. The HHR and the HHRA are hosted and maintained by NHS South, Central and West Commissioning Support Unit (CSU). The Governance body is the HHR Information Governance Group (HHRIGG), which ensures the security and confidentiality of the HHR and HHRA and considers issues of data integration or data sharing. Linked data contained within HHRA includes:

- Primary care data:

Coded clinical entries made during routine patient care

- Secondary care data:

Radiology and pathology data

Inpatient, outpatient and emergency department (ED) secondary uses service (SUS) data.

Primary care coding within the HHRA uses Read codes, which are the standard clinical terminology system used in primary care in the UK. The Read code system comprises a detailed hierarchy of codes describing diagnoses, symptoms, signs, processes of care, investigations, administrative items, procedures and medication; $90 \%$ of UK practices use Read version 2 (V2) codes, which were used for the purpose of data capture for this study.

The HHRA allows full access to coded hospital activity data from SUS, thereby allowing quantification of respiratory-related hospital-based health care use to a much greater extent than is possible through databases accessing primary care data alone. The hospital data are the same as that used in contracting, accounting and NHS reporting processes, so high quality is assured.

The secondary care information used was Payment by Results data drawn from the SUS, which involves many quality control/validation processes applied at national level. For primary care information, basic data cleaning had already been performed within the NHS environment before data were imported into the HHR and HHRA. For this study, data cleaning involved excluding from the data set duplicated records and assessments with null and zero values and values deemed incompatible with life.
International Journal of COPD

\section{Publish your work in this journal}

The International Journal of COPD is an international, peer-reviewed journal of therapeutics and pharmacology focusing on concise rapid reporting of clinical studies and reviews in COPD. Special focus is given to the pathophysiological processes underlying the disease, intervention programs, patient focused education, and self management protocols.

\section{Dovepress}

This journal is indexed on PubMed Central, MedLine and CAS. The manuscript management system is completely online and includes a very quick and fair peer-review system, which is all easy to use. Visit http://www.dovepress.com/testimonials.php to read real quotes from published authors. 